\title{
Correction to: Synthesis and characterization for new Zn(II) complexes and their optimizing fertilization performance in planting corn hybrid
}

\author{
Ismail Althagaf ${ }^{1} \cdot$ Moataz Morad $^{1}$ - Aisha Y. Al-dawood ${ }^{1} \cdot$ Naema Yarkandy $^{1} \cdot$ Hanadi A. Katouah $^{1} \cdot$ Aisha S. Hossan ${ }^{4}$. \\ Abdalla M. Khedr ${ }^{1,5}$. Nashwa M. El-Metwaly ${ }^{1,6}$. Farag Ibraheem ${ }^{2,3}$
}

Published online: 4 February 2021

(c) Institute of Chemistry, Slovak Academy of Sciences 2021

\section{Correction to: Chemical Papers \\ https://doi.org/10.1007/s11696-020-01440-7}

The original version of this article has been corrected.

In the original version of this article, unfortunately the Table 6 has been misplaced after the first reference in the reference list and Farag Ibraheem has to be moved to the end of the authors list.

Table 6 Comparative physiological responses of corn hybrid plants to different fertilizer treatments

\begin{tabular}{|c|c|c|c|c|c|c|}
\hline \multirow[t]{2}{*}{ Treatment } & \multicolumn{4}{|c|}{ Photosynthetic pigments ( $\mu \mathrm{g} / \mathrm{g}$ F.WT) } & \multicolumn{2}{|c|}{$\begin{array}{l}\text { Carbohydrates } \\
\text { (mg/g Dwt) }\end{array}$} \\
\hline & Chlorophyll a & Chlorophyll b & Carotenoids & Total pigments & Sucrose & TSS \\
\hline $\mathrm{Zn}(\mathrm{II})-\mathrm{H}_{2} \mathrm{~L}^{2}$ & $23.15^{\mathrm{a}}$ & $7.45^{\mathrm{a}}$ & $6.36^{\mathrm{a}}$ & $36.97^{\mathrm{a}}$ & $1.57^{\mathrm{a}}$ & $2.80^{\mathrm{a}}$ \\
\hline $\mathrm{NH}_{4} \mathrm{NO}_{3}$ & $15.72^{\mathrm{b}}$ & $5.32^{\mathrm{b}}$ & $4.27^{\mathrm{b}}$ & $25.32^{\mathrm{b}}$ & $1.46^{\mathrm{b}}$ & $1.91^{\mathrm{b}}$ \\
\hline Non-fertilized & $10.69^{c}$ & $3.00^{\mathrm{c}}$ & $3.27^{\mathrm{c}}$ & $16.96^{\mathrm{c}}$ & $1.11^{\mathrm{c}}$ & $1.40^{\mathrm{c}}$ \\
\hline
\end{tabular}

Shown values are the means of various fractions of photosynthetic pigments, sucrose, and total soluble sugars. Means with different letters indicate significant statistical difference among treatments at $(P \leq 0.05)$
The original article can be found online at https://doi.org/10.1007/ s11696-020-01440-7.

\section{Nashwa M. El-Metwaly}

n_elmetwaly00@yahoo.com

1 Department of Chemistry, Faculty of Applied Science, Umm Al-Qura University, Makkah, Saudi Arabia

2 Alqunfodah Research Unit, Umm Al-Qura University, Makkah, Saudi Arabia

3 Botany Department, Faculty of Science, Mansoura University, Mansoura 35516, Egypt

4 Chemistry Department, Faculty of Science, King Khalid University, P.O. Box 9004, Abha, Saudi Arabia

5 Chemistry Department, Faculty of Science, Tanta University, Tanta, Egypt

6 Chemistry Department, Faculty of Science, Mansoura University, Mansoura, Egypt
Publisher's Note Springer Nature remains neutral with regard to jurisdictional claims in published maps and institutional affiliations. 